\title{
Nocturnal penile tumescent evaluation of erectile function in insulin-dependent diabetic men
}

\author{
R. C.Schiavi, C. Fisher, M. Quadland and A. Glover \\ Human Sexuality Program, Department of Psychiatry, Mount Sinai School of Medicine, New York, USA
}

\begin{abstract}
Summary. This study compared nocturnal penile erections in four age-matched groups of young subjects: diabetic patients with and without erectile problems, psychogenically impotent men and healthy control subjects. All men were assessed under similar conditions during three nights, each for a total of 156 study nights. Diabetic impotent men exhibited a significantly decreased number of erectile episodes $(p<0.05)$ and episodes of maximum tumescence per night $(p<0.01)$. They also spent significantly less time in tumescence $(p<0.005)$ and in simultaneous rapid eye movement sleep and tumescence $(p<0.005)$. Diabetic men without sexual problems, psychogenically impotent men, and normal control subjects did not differ. Diabetic men in both groups spent less sleep time in
\end{abstract}

rapid eye movement sleep and had longer latencies to onset of rapid eye movement. The decreased time in erection noted in impotent diabetic patients was no longer significant when adjusted for differences in duration of rapid eye movement sleep. In comparison to healthy control subjects and psychogenically impotent men, non-impotent diabetic men did show significantly diminished circumferential increases during erections, similar in degree to impotent diabetic patients $(p<0.05)$.

Key words: Diabetic impotence, nocturnal penile tumescence, sexual function, sleep.
During recent years the monitoring of nocturnal penile tumescence during sleep has been frequently used for the objective assessment of organic impairment in erectile capacity [1]. This method is based on the proposition that in psychogenic impotence, erections associated with rapid eye movement sleep are normal, in marked discrepancy with patients's sexual performance; while with organic impotence, nocturnal erections correspond closely to the patient's impaired walking erectile function. Karacan et al. [2, 3] and Fisher et al. [4] reported that diabetic patients, as a group, showed impaired nocturnal penile tumescence as evidenced by decreased total penile tumescent time, diminished duration and frequency of full erections and a reduction in the maximum increase in penile circumference. Hosking et al. [5], on the other hand, based on the observation that only six out of 30 impotent diabetic patients showed a maximum penile circumference increase of less than $15 \mathrm{~mm}$, concluded that in most diabetic men impotence is due to psychological factors.

Conclusions derived from nocturnal penile tumescent studies of diabetic patients are limited by the use of sleep data in the initial diagnostic assignment of patients introducing a bias towards finding differences between the organic and psychogenic groups and by the absence of diabetic men free from sexual problems evaluated under similar conditions.

The present study was conducted to compare changes in penile erections during sleep in four agematched groups formed on the basis of clinical criteria alone: impotent diabetic patients, diabetic men without sexual problems, psychogenically impotent men and normal control subjects.

\section{Subjects and method}

\section{Subjects}

Fifty-two men participated in this study: 13 normal men; 23 diabetic patients ( 12 without and 11 with erectile problems) and 16 psychogenically impotent patients. Socio-demographic and clinical characteristics of subjects are summarized in Table 1. Selection criteria were: aged 22-36 years, no evidence of organic disease other than diabetes, no significant psychopathology and no current or recent history of drug use other than anti-diabetic medication. Men with erectile impotence were mostly referred to the Human Sexuality Program for evaluation. All subjects had an extensive personal and psychosexual interview and, when not recently available, also underwent medical evaluation. Diagnostic categorization into four groups was made independently of information on nocturnal penile tumescence.

Impotence was defined as inability to achieve and sustain an adequate erection for insertion and thrusting until completion of the sex- 
Table 1. Clinical characteristics of the subjects studied

\begin{tabular}{|c|c|c|c|c|}
\hline & \multirow{2}{*}{$\begin{array}{l}\text { Normal } \\
\text { subjects }\end{array}$} & \multirow{2}{*}{$\begin{array}{l}\text { Psychogeni- } \\
\text { cally impo- } \\
\text { tent patients }\end{array}$} & \multicolumn{2}{|c|}{$\begin{array}{l}\text { Insulin-dependent } \\
\text { diabetic patients }\end{array}$} \\
\hline & & & $\begin{array}{l}\text { No erectile } \\
\text { problems } \\
(n=12)\end{array}$ & $\begin{array}{l}\text { Erectile } \\
\text { problems } \\
(n=11)\end{array}$ \\
\hline Age (years) & $\begin{array}{l}27.9 \pm 0.9 \\
(23-33)\end{array}$ & $\begin{array}{l}29.0 \pm 1.2 \\
(22-36)\end{array}$ & $\begin{array}{l}27.1 \pm 0.8 \\
(25-32)\end{array}$ & $\begin{array}{l}30.0 \pm 0.8 \\
(24-34)\end{array}$ \\
\hline Marital status & & & & \\
\hline Single & 10 & 11 & 9 & 6 \\
\hline Married & 2 & 3 & 1 & 3 \\
\hline $\begin{array}{l}\text { Divorced } / \\
\text { separated }\end{array}$ & 1 & 2 & 2 & 2 \\
\hline $\begin{array}{l}\text { Duration of } \\
\text { impotence } \\
\text { (years) }\end{array}$ & - & $\begin{array}{l}5.6 \pm 1.2^{\mathrm{a}} \\
(1-17)\end{array}$ & - & $\begin{array}{l}4.3 \pm 0.7 \\
(2-8)\end{array}$ \\
\hline $\begin{array}{c}\text { Duration of } \\
\text { diabetes } \\
\text { (years) }\end{array}$ & - & - & $\begin{array}{l}9.6 \pm 2.0 \\
(1-20)\end{array}$ & $\begin{array}{l}12.3 \pm 2.0 \\
(4-29)\end{array}$ \\
\hline
\end{tabular}

Results expressed as mean \pm SEM with ranges in parentheses.

a Value excludes two primary impotent men

ual act. Assignment of diabetic subjects to the sexually dysfunctional group was based on normal sexual competency prior to the onset of diabetes, a temporal relationship between diabetes and the progressive, persistent and global development of erectile impotence and lack of evidence of psychological causation. Assignment of impotent men to the psychogenic category was based on evidence that relationship problems were temporarily related to onset of erectile difficulties; the report that erectile impotence was limited to a specific partner or that the subject was able to achieve a full erection by masturbation and no evidence of medical illnesses. Control volunteers and non-dysfunctional diabetic subjects reported a lifelong history essentially free from erectile problems. None of the diabetic and psychogenically impotent patients had a previous history of neurological or renal disease, cardiovascular problems, thyroid dysfunction or alcohol abuse. All diabetic subjects were taking insulin and based on information from the referring physician and the medical evaluation at the time of the study, they were within reasonably good metabolic control.

\section{Methods}

The subjects were assessed under similar conditions during three nights variably spaced within 1 month for a total of 156 study nights. Methods of procedure and analysis employed in our sleep laboratory have been described previously in detail [1, 4]. EEG and eye movements were monitored continuously throughout the night by means of monopolar parietal and occipital leads and electrodes attached to the left and right outer canthi. Sleep records were scored according to standardized criteria [6]. Penile tumescence was recorded by means of two strain gauge loops placed around the penis $2.5 \mathrm{~cm}$ from the base and just caudal to the glans. During the third night, visual checks were carried out to ascertain degree of erection in relation to the recorded increase in penile circumference. This step is necessitated by the marked variations in penile circumference increases associated with full erections that ranged from 15 to $45 \mathrm{~mm}$. Quantitative comparisons were made on mean values of degree, frequency and duration of tumescence recorded during the three nights. These variables are defined as follows: Degree: increase in penile circumference over the flaccid state measured in millimeter at the base. Deviations from baseline recordings of $81-100 \%$ and $25-80 \%$ of the greatest penile circumference estimated to be full by direct observation were considered to be maximum and partial episodes respectively. Frequency: mean number of maximum and partial tumescent episodes per night and during rapid eye movement sleep. Duration: mean time per night spent in tumescence, above $80 \%$ of full tumescence and in simultaneous rapid eye movement sleep and tumescence.

\section{Statistical analysis}

Statistical comparisons among the four groups were made by analysis of variance. If the results on this test were significant, further statistical analysis by the Fisher's protected least significant difference test [7] was carried out to identify the source of the statistical difference.

\section{Results \\ Clinical features}

The mean age at clinical onset of diabetes was 17.5 years (range 7-24 years) for men without sexual problems and 17.6 years (range 5-25 years) for impotent diabetic patients. The onset of erectile problems occurred from 6 months to 25 years after diabetes was diagnosed. Diabetic impotent subjects described progressive difficulties in gaining and maintaining erections during intercourse and masturbation and reported absent or only partial erections while awakening during the night or early morning. All impotent diabetics retained orgasmic capacity but two experienced retrograde ejaculation and two others had ejaculates in decreased amount and density. Five diabetic patients responded to the development of erectile difficulties with emotional reactions that included fear of failure, anticipatory anxiety, frustration and sexual avoidance.

Among the diabetic men without sexual problems, three indicated having experienced transient erectile difficulties during past periods of metabolic decompensation, but they denied erectile problems during the 6 months preceding the study. Only one subject in each of the diabetic groups indicated a decrease in sexual desire that was, in the case of the impotent diabetic man, secondary to the erectile problem. Diabetic complications were present in four patients, all in the impotent group: two suffered from retinopathy and two had severe neuropathy in their legs.

Most of the men in the psychogenically impotent group reported a life-long history of intermittent erectile failure, with the duration of the last episode of this ranging from 1 to 17 years. Two subjects had never been able to achieve intercourse, but they had consistent full erections by masturbation. Only two men in the psychogenically impotent group had a moderate decrease in sexual desire secondary to the development of erectile difficulties.

\section{Sleep variables}

Sleep variables recorded during the three study nights are summarized in Table 2. Sleep patterns were within the normal range in all subjects. There were no significant differences between groups in duration of sleep, percentage time awake following onset of sleep and number of rapid eye movement periods per night. Significant differences were observed, however, in duration of rapid eye movement sleep $(p<0.005)$ and in percentage of sleep time during the rapid eye movement 
Table 2. Sleep parameters in subjects studied

\begin{tabular}{|c|c|c|c|c|c|}
\hline \multirow[b]{3}{*}{ Sleep time (min) } & \multirow{2}{*}{$\begin{array}{l}\text { Normal } \\
\text { subjects } \\
(n=13)\end{array}$} & \multirow{2}{*}{$\begin{array}{l}\text { Psychogenically } \\
\text { impotent patients } \\
(n=16)\end{array}$} & \multicolumn{2}{|c|}{$\begin{array}{l}\text { Insulin-dependent } \\
\text { diabetic patients }\end{array}$} & \multirow[b]{2}{*}{$p$} \\
\hline & & & $\begin{array}{l}\text { No erectile } \\
\text { problems }\end{array}$ & $\begin{array}{l}\text { Erectile } \\
\text { problems }\end{array}$ & \\
\hline & $\begin{array}{c}406 \pm 10 \\
(337-448)\end{array}$ & $\begin{array}{c}406 \pm 10 \\
(362-472)\end{array}$ & $\begin{aligned} 405 & \pm \quad 7 \\
(368 & -447)\end{aligned}$ & $\begin{array}{c}371 \pm 14 \\
(261-417)\end{array}$ & NS \\
\hline Awake (percentage time) & $\begin{array}{cc}4.6 \pm & 0.7 \\
(1.2- & 11.0)\end{array}$ & $\begin{array}{cc}4.4 \pm & 0.5 \\
(2.8- & 10.7)\end{array}$ & $\begin{array}{cc}5.0 \pm & 0.7 \\
(2.0- & 10.5)\end{array}$ & $\begin{array}{c}6.1 \pm 1 \\
(3.7-14.3)\end{array}$ & NS \\
\hline Number of rapid eye movement periods & $\begin{array}{cc}4.0 \pm & 0.2 \\
(3.0- & 5.0)\end{array}$ & $\begin{array}{cc}4.2 \pm & 0.1 \\
(3.3- & 5.3)\end{array}$ & $\begin{array}{cc}3.9 \pm & 0.2 \\
(2.3- & 5.0)\end{array}$ & $\begin{array}{cc}3.6 \pm & 0.2 \\
(3.0- & 4.6)\end{array}$ & NS \\
\hline Rapid eye movement time (min) & $\begin{array}{c}83 \pm 5 \\
(53-115)\end{array}$ & $\begin{aligned} 91 & \pm 5 \\
(51 & -134)\end{aligned}$ & $\begin{aligned} 73 & \pm 6 \\
(36 & -108)\end{aligned}$ & $\begin{array}{r}61 \pm 5.5 \\
(32-85.5)\end{array}$ & $<0.01$ \\
\hline Rapid eye movement time: sleep time (\%) & $\begin{array}{c}20 \pm 1 \\
(14-27.5)\end{array}$ & $\begin{array}{c}21 \\
(15-29)\end{array}$ & $\begin{array}{c}\left.17 \pm \quad \begin{array}{c}1 \\
(10\end{array}-24\right)\end{array}$ & $\begin{array}{ll}16 & \pm \\
(7 & -22)\end{array}$ & $<0.05$ \\
\hline
\end{tabular}

Mean \pm SEM of three study nights; values in parentheses represent range

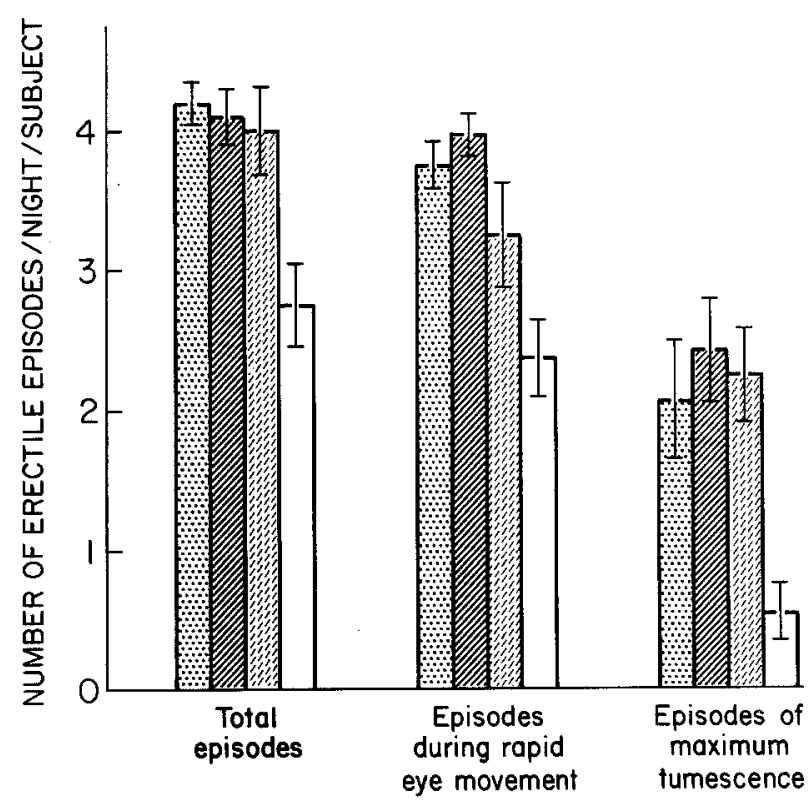

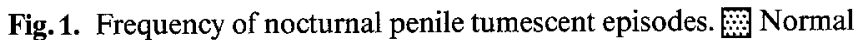
subjects $(n=13)$; $\mathbb{Z}$ psychogenically impotent men $(n=16)$; 䍗 diabetic patients without erectile problems $(n=12) ; \square$ diabetic patients with erectile problems $(n=11)$. Bars $=$ mean \pm SEM of three nights per subject

stage $(p<0.005)$. The two diabetic groups were similar, but both spent significantly less sleep time in rapid eye movement sleep than the psychogenically impotent group $(p<0.05)$; impotent diabetic men also differed statistically on these variables from normal subjects $(p<0.05)$. Rapid eye movement latency, defined as the length of time from onset of sleep (stage 1) to the appearance of rapid eye movement sleep, was prolonged in both diabetic groups; diabetic men without sexual problems spent a significantly longer sleep period before rapid eye movement sleep than the other three groups (F 2.99; df 3,$48 ; p<0.05$ ).

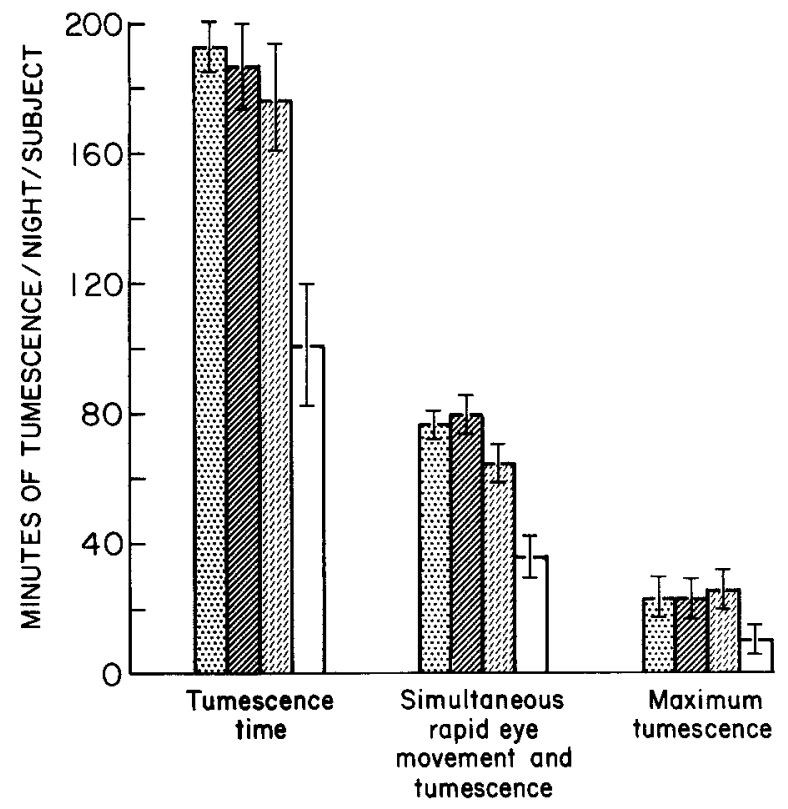

Fig. 2. Duration of nocturnal penile tumescent episodes in the four groups. 誵 Normal subjects $(n=13)$; $\mathbb{Z}$ psychogenically impotent men $(n=16)$; 罡 diabetic patients without erectile problems $(n=12)$; $\square$ diabetic patients with erectile problems $(n=11)$. Bars $=$ mean \pm SEM of three nights per subject

\section{Tumescent parameters}

A cyclic pattern of episodic erectile activity closely associated with rapid eye movement sleep was observed in most subjects. Frequency of nocturnal tumescent variables are shown in Figure 1. There were significant differences among groups in the total number of episodes per night (F 4.2; df 3,48; $p<0.05)$, number of episodes during rapid eye movement sleep ( $\mathrm{F} 10.3$; df 3,48 ; $p<0.001)$ and number of episodes that reached maximum tumescence ( $\mathrm{F} 4.7 ; \mathrm{df} 3,47 ; p<0.01)$. In all three variables the difference rested on the diabetic impotent 


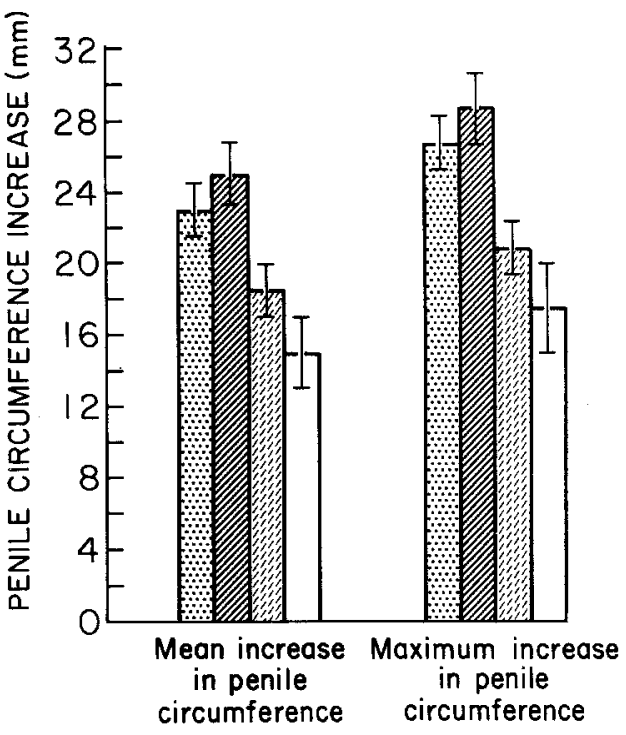

Fig.3. Circumference increases of the penis during tumescent episodes. Normal subjects $(n=13)$; 暞 psychogenically impotent men $(n=16)$; 疄 diabetic patients without erectile problems $(n=12)$; $\square$ diabetic patients with erectile problems $(n=11)$. Bars $=$ mean \pm SEM of three nights per subject.

group with markedly fewer episodes per night relative to the other groups. No statistical differences were noted in frequency of partial tumescent episodes per night or the number of tumescent episodes during non-rapid eye movement sleep.

Data on duration of tumescent episodes in the four groups are summarized in Figure 2. There were no significant mean differences among the normal, psychogenic and non-dysfunctional diabetic subjects. In contrast, impotent diabetic men spent considerably less time in tumescence $(\mathrm{F} 8.1 ; \mathrm{df} 3,48 ; p<0.005)$ and in simultaneous rapid eye movement and tumescence (F 10.2; df 3,$48 ; p<0.005$ ). Diabetic impotent men also spent less time in maximum tumescence than the other three groups, but because of the proportionately large intra-group variability, this variable did not differ statistically.

To control for differences in rapid eye movement sleep among groups, duration of tumescence was also calculated as a percentage of total rapid eye movement sleep time. When tumescence was adjusted for differences in duration of rapid eye movement, the decreased tumescent time noted in the impotent diabetics was no longer significant when compared with the other groups.

The degree of circumferential change measured at the base of the penis during tumescent episodes is illustrated in Figure 3. There were statistical differences between groups in increases in mean penile circumference over the tumescent episodes (F 6.7; df 3,$48 ; p<0.005$ ) and in the average increases in maximum penile circumference recorded during the three nights (F 7.0; df 3,$48 ; p<0.005$ ). The non-dysfunctional and impotent diabetic groups did not differ from each other in the two measures, but both had significantly diminished mean circumferential increases during erectile episodes than the normal and psychogenically impotent groups $(p<0.05)$.

\section{Discussion}

Comparison of mean values in groups constituted on the basis of clinical criteria alone confirms the hypothesis that nocturnal penile tumescent recordings differentiate organically impotent diabetic men from diabetic patients without erectile problems, psychogenically impotent subjects and normal control men. The results showed that specific variables, such as the total number of erectile episodes per night, frequency of maximum tumescent episodes and duration of simultaneous rapid eye movement sleep and tumescence, were better able to differentiate the impotent diabetic group from the others.

Wide individual differences in nocturnal penile tumescent measures were observed within groups: three normal men, two subjects with impotence and one diabetic patient without erectile problems had markedly decreased or absent maximum tumescent episodes. There is evidence that psychological factors may play a significant role in the abnormal tumescent patterns of some subjects without identifiable medical illnesses [8-12]. It is of note than in the present study the two patients characterized as psychogenically impotent, who did not exhibit a single full tumescent episode during the three study nights, responded to psychotherapy with a lasting capacity for normal sexual function.

Lack of assessment of diabetic men without sexual problems has seriously limited the interpretation of nocturnal tumescent changes in previous studies on diabetic patients. Although diabetic men free from erectile difficulties did not differ from the normal and psychogenically impotent groups in duration and frequency of erectile episodes, they showed significantly diminished penile circumference increases similar in degree to impotent diabetic men. It seems reasonable to speculate that some diabetic men without sexual problems already had an incipient and subclinical impairment in erectile capacity, although not of sufficient magnitude to interfer with penetration. Some of these subjects, however, may be at risk for the development of erectile failure depending on the interactive effects of psychosocial stressful conditions, metabolic decompensation or drug ingestion.

The observation that both diabetic groups did not differ significantly in the degree of increases in penile circumference has important consequences in view of the fact that this variable has been frequently used to categorize subjects as organically or psychogenically impotent $[3,5,13]$. The present findings suggest that nocturnal penile tumescent parameters, such as the number of total or maximum erectile episodes per 
night, although less sensitive, may be better diagnostic discriminators of organic impotence because they differentiate relevant degrees of erectile impairment. Since there are considerable individual variations in penile circumference increases associated with full tumescence [1], it is important to conduct systematic observations during one study night to ascertain the degree of circumferential increase associated with sufficient rigidity for penetration.

The polygraphic assessment of sleep in conjunction with nocturnal penile tumescent variables disclosed unexpected information. Diabetic men in both groups had longer latencies to the onset of rapid eye movement sleep and spent significantly less time in this sleep stage. The possibility that metabolic abnormalities associated with diabetes may disturb brain function and rapid eye movement activity during sleep requires further investigation. To our knowledge, no systematic EEG studies of diabetic men during sleep have been reported. From a practical standpoint, this observation strongly suggests that sleep staging needs to be taken into account in the evaluation of nocturnal tumescent data among diabetic subjects. When duration of tumescence was adjusted to percentage of time in rapid eye movement sleep, the decreased time in erection noted in impotent diabetic men was no longer significant when compared with the other three groups. Lack of consideration of sleep staging may lead to erroneous diagnostic decisions by attributing to erectile capacity differences in sleep patterns among various clinical entities.

In conclusion, the present study extends our previous observations on the validity of nocturnal penile tumescent monitoring for the assessment of organic impairment in erectile capacity $[1,4]$. It also provides a cautionary note regarding the uncritical application of this widely-used method for differential diagnosis of erectile disorders.

Acknowledgments. The authors express their appreciation to Drs. E. Rayfield and H. Dolger. This research was carried out with the support of USPHS research grants AM 20845 and MH 27513 and a grant from the New Land Foundation.

\section{References}

1. Schiavi RC, Fisher C (1982) Assessment of diabetic impotence: measurement of nocturnal erections. Clinic Endocrinol Metab 11: 769-784

2. Karacan I, Scott FB, Salis PJ, Attia SL, Ware JC, Altinel A, Williams RL (1977) Nocturnal erections, differential diagnosis of impotence and diabetes. Biol Psychiatr 12:373-380

3. Karacan I, Salis PJ, Ware JC, Jervent B, Williams RL, Scott, FB, Attia SL, Beutler LE (1978) Nocturnal penile tumescence and diagnosis in diabetic impotence. Am J Psychiatry 135: 191-197

4. Fisher C, Schiavi RC, Edwards A, Davis D, Reitman M, Fine J (1979) Evaluation of nocturnal penile tumescence in the differential diagnosis of sexual impotence. Arch Gen Psychiatry 36: $431-437$

5. Hosking DJ, Bennet T, Hampton JR, Evans DF, Clarke AJ, Robertson $G$ (1979) Diabetic impotence: studies of nocturnal erection during REM sleep. Br Med J 2:1394-1396

6. Rechteschaffen A, Kales A (1968) A manual of standardized terminology. Techniques and scoring system for sleep stages in human subjects. Government Printing Office. Washington, DC

7. Snedecor GW (1956) Statistical methods. The Iowa State University Press, 5th edn, p 251

8. Fisher C (1966) Dreaming and sexuality. In: Loewenstein RM, Newman LM, Schur M (eds) Psychoanalysis: a general psychology - essays in honor of Heinz Hartman. International University Press, New York, pp 537-563

9. Karacan I, Goodenough DR, Shapiro A, Starker S (1966) Erection cycle during sleep in relation to dream anxiety. Arch Gen Psychiatry $15: 183-189$

10. Jovanović UJ (1969) Der effekt der ersten untersuchungsnacht auf die erektionen im schlaf. Psychother Psychosom 17: 295-308

11. Jovanović UJ (1972) Sexuelle reaktionen und schlafperiodik bei menschen: Ergebnisse experimenteller untersuchungen. Beitr Sexualforsch 51: 1-292

12. Roose SP, Glassman AH, Walsh BT, Cullen K (1982) Reversible loss of nocturnal penile tumescence during depression: a preliminary report. Neuropsychobiology $8: 284-288$

13. Marshall $P$, Surridge DM, Delva M (1981) The role of nocturnal penile tumescence in differentiating between organic and psychogenic impotence: the first stage of validation. Arch Sex Behav 10: $1-10$

Received: 12 April 1984

and in revised form: 19 November 1984

Dr. Raul C. Schiavi

Human Sexuality Program

Mount Sinai School of Medicine

19 East 98th Street, Suite 9A

New York, NY 10029

USA 